http://www.jfas.info

\title{
DEVELOPING HEALTH STATUS INDEX USING FACTOR ANALYSIS
}

M. Mohamad ${ }^{1}$, H. Juahir ${ }^{2,}$, N. A. M. Ali ${ }^{1}$, M. K. A. Kamarudin ${ }^{2}$, F. Karim ${ }^{1}$ and N. Badarilah ${ }^{1}$

${ }^{1}$ Faculty of Economics and Management Sciences, Universiti Sultan Zainal Abidin, Gong

Badak Campus, 21300 Kuala Nerus, Terengganu, Malaysia

${ }^{2}$ East Coast Environmental Research Institute (ESERI), Universiti Sultan Zainal Abidin, Gong

Badak Campus, 21300 Kuala Nerus, Terengganu, Malaysia

Published online: 08 August 2017

\begin{abstract}
This paper intends to develop health status index among drug abuse prison inmates in Malaysia. A self-admistered questionnaire distributed to 1753 respondents. In this study, to calculate the health status index number of drug abuse inmates, descriptive and factor analyses applied. The data based on 10 indicators of health status were analyzed using factor analysis (principal component, varimax rotation) and two factors extracted after analyzation, each identified as physical health and mental health. 55\% of the total variance achieved. The descriptive and factor analyses applied to quantify the multidimensional vagueness term of "health", that is somewhat never been completely studied. The study output, five health group classified poor (3\%), bad (19\%), moderate (41\%), good (29\%) and excellent (8\%).
\end{abstract}

Keywords: index; factor analysis; descriptive analysis; health questionnaire.

Author Correspondence, e-mail: hafizanjuahir@unisza.edu.my

doi: http://dx.doi.org/10.4314/jfas.v9i2s.6 


\section{INTRODUCTION}

The developing of an index of health is a challenge to measure the health status of a specified population. Nevertheless, the measurement results in various problems, not the least of which is an operational definition of health. In this research, the appropriate health definition is significantly as a state of complete in terms of physically, mentally and socially well-being [1]. Therefore, this study use the health terminology refers to the various health-related conditions, by which to include the emotional, degree of physical or mental functional and perceptions of health status physically or mentally. The functional of physical and mental refers to the ability of a person to perform particular activities that require physical action and cognitive processing [2].

The calculation of an adequate index of health raises questions is to define health and health status indicator. Two main factors are importantly be included under the developing index number, viz. a) meaningful and understandable, and b) sensitivity to variation in the phenomenon being measured, c) Assumptions underlying the index are theoretically justifiable and intuitively reasonable, d) To have clearly defined components, e) Each components make an independent contribution to differences in the phenomenon being measured and f) Derivable data feasible to obtain [3].

This study aims to measure the health level of drug abuse among the prison inmates in Malaysia. The purpose of this study is to identify the individual health indicators, describing the particular aspects of health and to determine the overall index number for the drug abuse inmate in Malaysia prison. Measurement of health through the calculated index serves the function as an appropriate tool applied to improve the collective health in an efficient manner.

\section{METHODOLOGY}

\subsection{Data Collection}

The data was collected from thirteen [4], prisons selected in Peninsular Malaysia through the interview sessions using a structured questionnaire during the period from the month of April to June 2015. Since these prisons are widely scattered in terms of geographical location, thereby the study area of the Peninsular Malaysia divided into four divisions/regions namely Eastern, Northern, Southern and Central.

The Eastern Region comprises of the states of Kelantan (Pengkalan Chepa), Terengganu (Marang) and Pahang (Bentong and Penor) prisons. The Northern region covers the states of Kedah (Pokok Sena and Sunga Petani) and Pulau Pinang (Seberang Perai) prisons. The 
Southern Region comprises the area of Johor Bharu (Kluang and Simpang Renggam). Lastly, the prime area, the Central region covers the states of Selangor (Kajang), Negeri Sembilan (Seremban and Jelebu) and Perak (Tapah) prisons. Once the prisons chosen, the respondents selected based on a simple random-sampling approach from a sampling frame provided by the prison authority. This technique applied to fulfil the minimum number of respondent, serve as representative for the sampling [5]. 1753 respondents involved in the study.

\subsection{Measurement}

Health status measured using the Medical Outcomes Study 36-item Short-Form Health Survey (SF-36). The SF 36 is a survey that measured the physical and mental health level via eight health domains: physical functioning, general mental health of which covers the psychological distress as well as the psychological well-being, bodily pain, role limitations due to physical health, vitality, general health perceptions, social functioning and role limitations due to emotional health [6]. Respondents were instructed to indicate the extent of their agreement or disagreement to the items measuring HS using a measurement scale, ranging from 1 (strongly disagree) to 10 (strongly agree).

\subsection{Statistical Analysis}

\subsubsection{Factor Analysis}

Factor Analysis (FA) applied to identify the underlying dimensions of health level or status among the drug abuse inmates. Further, the FA application enables the relationship inference between the dependent and independent variables [7]. Varimax factor in the FA enables every variable link with only one principal component, by which each component is uncorrelated with other components [8]. The VFs values which are greater than $0.75(>0.75)$ is considered as "strong", the values range from $0.50-0.75(0.50 \geq$ factor loading $\geq 0.75)$ is considered as "moderate" and the values range from $0.30-0.49(0.30 \geq$ factor loading $\geq 0.49)$ is considered as "weak" factor loadings [9-10]. In practice, only factor loadings with absolute values greater than 0.75 selected for the principal component interpretation (11-10). The fundamental model of FA expressed as the Equation (1):

$\mathrm{Z}_{\mathrm{ij}=} \mathrm{a}_{\mathrm{f} 1} \mathrm{f}_{1 \mathrm{i}}+\mathrm{a}_{\mathrm{f} 2} \mathrm{f}_{2 \mathrm{i}}+\cdots+\mathrm{a}_{\mathrm{fm}} \mathrm{f}_{\mathrm{mi}}+\mathrm{e}_{\mathrm{fi}}$

where $\mathrm{z}$ is the measured value of a variable, $\mathrm{a}$ is the factor loading, $\mathrm{f}$ is the factor score, e represents the residual term accounting for errors or other sources of variation, $i$ is the sample number, $\mathrm{j}$ is the variable number and $\mathrm{m}$ is the total number of factors.

In this study, 10 variables involved in the factor analysis. The number of factors extracted can be defined by the user and there are techniques available in XLSTAT 2013 software 3.1 that 
can be used to decide the number of factors. One of the most commonly used techniques is the eigenvalue rule. Principal Components (PCs) with the eigenvalues greater than 1.0 deems to be significant and considered in this study [11]. In the present study, the Kaiser-Meyer-Olkin (KMO), a Measure of Sampling Adequacy (MSA) applied to detect the multicollinearity in the data, so that the appropriateness of factor analysis is achievable. To be specific, the sampling adequacy prediction based on the independent and dependent variables correlations as well as partial correlations. The KMO measure compares the sizes of the observed correlation coefficients with the magnitudes of the partial correlation coefficients. If the variables in fact have common factors, the partial correlation coefficients relatively smaller compared to total correlation coefficient. The maximum values of KMO can be 1.0, the value of 0.90 is considered as 'Excellent', 0.80 ('good'), 0.70 ('moderate'), 0.60 ('poor') and 0.50 ('weak') [12].

\subsubsection{Developing Index}

Developing index derived from the items in the SF36 questionnaire. As a first step in the computation of a single index, factor score of each case estimated. To compute the factor scores for a given case of a given factor, the case standardized score on each variable multiply with the factor loading of the variable for the given factor and summed these products. This qualitative analysis performed using the XLSTAT 2013 software. The two factors explained $54.55 \%$ of the total variation with the first and second factors, explaining $29.17 \%$ and $25.38 \%$ respectively. Table 3 illustrates on how the individual index numbers were calculated. The percent variance used to weight each factor score across all factors by using the following formula:

$$
\left.\mathrm{HS}_{\mathrm{i}}=\mathrm{V}_{1} \mathrm{~F}_{1}+\mathrm{V}_{2} \mathrm{~F}_{2}\right)+\cdots \mathrm{V}_{\mathrm{n}} \mathrm{F}_{\mathrm{n}} / 100
$$

where HS represents the index value of a variable, $\mathrm{V}$ is the factor loading, $\mathrm{F}$ is the factor score and $\mathrm{n}$ is the sample number.

To compute the factor scores for a given case for a given factor, the case standardized score on each variable multiplied with the corresponding factor loadings of the variable for the given factor, and summed these products. The calculation was carried out using XLSTAT 2013 Software version 3.1 and factor scores were saved as variables in subsequent calculations involving factor scores.

\section{RESULTS AND ANALYSIS}

The results of the descriptive analysis and factor analysis based on the varimax rotation are 
presented in Table 1.

\subsection{Descriptive analysis}

In variable selection, the descriptive analyses performed for all the variables, based on means and standard deviations (refer Table 1). Descriptive analysis provides the decision on which variables that supposed to include in the analysis.

Table 1. Results from descriptive and FA varimax rotation factor matrix

\begin{tabular}{|c|c|c|c|c|}
\hline Item & Mean & Standard Deviation & Factor 1 & Factor 2 \\
\hline SK1 & 5.3702 & 2.9337 & 0.6290 & \\
\hline SK2 & 5.0850 & 3.0150 & 0.7465 & \\
\hline SK3 & 5.4392 & 3.1029 & 0.7722 & \\
\hline SK4 & 5.5299 & 2.4148 & 0.5350 & \\
\hline SK5 & 5.3788 & 2.5257 & 0.5994 & \\
\hline SK6 & 5.3776 & 2.4218 & 0.5650 & \\
\hline SK7 & 6.4067 & 2.5274 & & 0.7923 \\
\hline SK8 & 6.5077 & 2.4986 & & 0.8942 \\
\hline SK9 & 6.2824 & 2.5642 & & 0.8847 \\
\hline SK10 & 5.6703 & 2.7859 & & 0.7982 \\
\hline \multicolumn{3}{|c|}{ KMO Measure of Sampling Adequacy } & \multicolumn{2}{|c|}{0.8113} \\
\hline \multicolumn{3}{|c|}{ Eigenvalue } & 3.3584 & 2.0963 \\
\hline \multicolumn{3}{|c|}{ Variability (\%) } & 29.17 & 25.38 \\
\hline \multicolumn{3}{|c|}{ Cumulative (\%) } & 29.17 & 54.55 \\
\hline
\end{tabular}

* Note: SK1 (Bending, kneeling or stooping); SK2 (Walking several blocks); SK3 (Walking one block); SK4 (accomplished less than you would like); SK5 (Had difficulty performing the work or other activities, for example it took extra effort); SK6 (Cut down on the amount of time you spent on work or other activities); SK7 (I feel full of pep); SK8 (I felt calm); SK9 (I felt peaceful) and SK10 (I have been a happy person).

\subsection{Factor Analysis Varimax Rotation}

The results of FA using varimax rotation presented in Table 1. The original questionnaire based on 36 reliable data, but after the pilot test only 10 indicators available. Due to this constraint on health information, the 10 indicators serve as the best possible data among drug 
abuse in Malaysia Prison. Two factors accounted for $54.55 \%$ of the total variance in the data. For the first factor, SK2 and SK3 showed strong loadings. The first factor accounted for $29.17 \%$ of the total variation. We may interpret this factor as a measure of the physical health.

For the second factor, all the four factors (SK7, SK8, SK9 and SK10) showed the higher positive loadings. The second factor accounted for $25.38 \%$ of the variance. This factor is considerably reasonable represents the mental health. To be more specific, it means that better mental health is associated with high psychological distress as well as psychological well-being.

The KMO shows that the Kaiser-Meyer-Olkin of health status recorded as 0.8113 signifies for the factor analysis of the variables can be subsequently preceded for further analysis. Fig. 1 plots each eigenvalues of the factors. Based on the screen plot, only two factors considered for analysis.

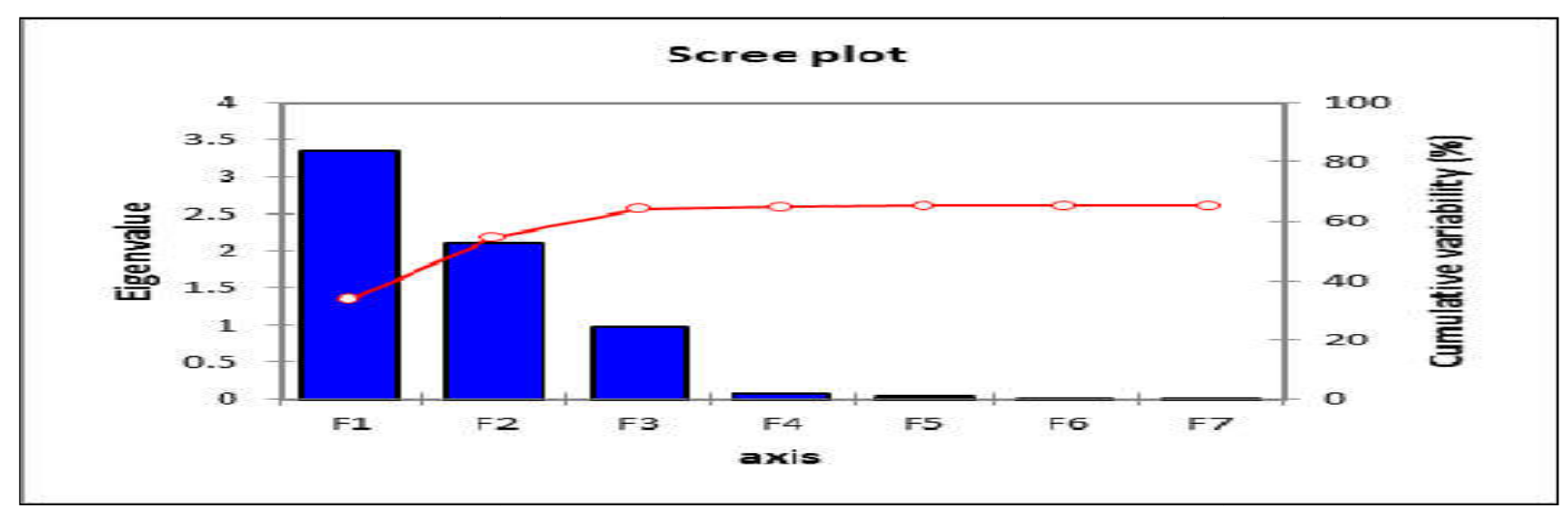

Fig.1. Screeplot of eigenvalues of factors

\subsection{Classification of Observations into Health Status Groups}

The drug abuse inmates in Malaysia Prison is ranked according to health group viz. poor, bad, moderate, good and excellent according to frequencies distribution as shown in Table 2. We classified 1753 cases of drug abuse inmates into health groups (Poor, Bad, Moderate, Good and Excellent). The health groups as presented in Table 3 reveals the results as of 3\%, 19\%, $41 \%, 29 \%$ and $8 \%$; represent poor, bad, moderate, good and excellent health status index respectively. 
Table 2. 5 bin using frequencies distribution

\begin{tabular}{|c|c|c|c|c|c|}
\hline-0.27437 & Frequency & $\begin{array}{c}\text { Cummulative } \\
\text { Frequency }\end{array}$ & $\%$ & $\begin{array}{c}\text { Cummulative } \\
\%\end{array}$ & $\begin{array}{l}\text { Health } \\
\text { Group }\end{array}$ \\
\hline-1.078 & 59 & 59 & $3.37 \%$ & $3.37 \%$ & Poor \\
\hline-0.675 & 333 & 392 & $19.01 \%$ & $22.37 \%$ & $\mathrm{Bad}$ \\
\hline-0.272 & 719 & 1111 & $41.04 \%$ & $63.41 \%$ & Moderate \\
\hline 0.132 & 503 & 1614 & $28.71 \%$ & $92.12 \%$ & Good \\
\hline 0.535 & 138 & 1752 & $7.88 \%$ & $100.00 \%$ & Excellent \\
\hline & $\begin{array}{l}\text { good } \\
29 \%\end{array}$ & $\begin{array}{l}\text { cellent } \\
8 \%\end{array}$ & $\begin{array}{l}\text { poor } \\
3 \%\end{array}$ & $\begin{array}{l}\text { oderate } \\
41 \%\end{array}$ & \\
\hline
\end{tabular}

Fig.2. The health group index 
Table 3. An illustration of calculated indices utilizing weighted score

\begin{tabular}{|c|c|c|c|c|}
\hline Cases & F1 & $\mathbf{F} 2$ & Initial Index & Health Group \\
\hline Obs1 & -1.3095 & 0.4241 & -0.2743 & $\mathrm{Bad}$ \\
\hline Obs 2 & 1.0727 & 0.1112 & 0.3411 & Good \\
\hline Obs3 & 0.1230 & 0.4974 & 0.1621 & Good \\
\hline Obs4 & 1.2088 & 0.7424 & 0.5410 & Excellent \\
\hline Obs5 & -0.4604 & -1.5678 & -0.5322 & $\mathrm{Bad}$ \\
\hline Obs6 & 0.6029 & 0.2661 & 0.2434 & Good \\
\hline Obs 7 & 0.1518 & 1.0154 & 0.3019 & Good \\
\hline Obs 8 & 0.2515 & 0.3820 & 0.1701 & Good \\
\hline Obs9 & 1.2084 & -0.0078 & 0.3505 & Good \\
\hline . & - & $\cdot$ & $\cdot$ & • \\
\hline . & $\cdot$ & - & $\cdot$ & • \\
\hline$\cdot$ & • & • & $\cdot$ & - \\
\hline Obs1748 & 0.5234 & -1.2876 & -0.1741 & Excellent \\
\hline Obs1749 & -0.3462 & -1.0250 & -0.3611 & Good \\
\hline Obs1750 & -0.8252 & -0.9242 & -0.4752 & Good \\
\hline Obs1751 & -1.1368 & -0.5396 & -0.4685 & $\mathrm{Bad}$ \\
\hline Obs 1752 & 0.5005 & 0.2700 & 0.2145 & Good \\
\hline Obs 1753 & -0.5312 & -0.1071 & -0.1821 & Moderate \\
\hline
\end{tabular}

\section{DISCUSSION}

Findings from this study indicate that physical health negatively affects drug abuse inmates' health status, but not on mental health of which remained stable. Those aspects of health status (bodily pain, general health, physical functioning and vitality) were most likely to be impaired at time of imprisonment. The indication poor in physical health from this analyses is consistent with the results from the previous study as the physical health components did not improve significantly and remained lower than the general population [4]. This findings supported the study conducted by [4] where 60000 prisoners in Africa, Asia, Australia, Europe and North America were physically unhealthy due to lack of physical activities [13]. It 
noted that the lacking of the physical activities attributed significantly to the health-related issues among prisoners. In Malaysia, old prison institutions like Seremban and Kajang unfortunately having insufficient space to facilitate the prisoners with the workout facilities to improve health and fitness [14].

However, the mental well-being of these inmates, as measured through the SF-36 has further improved. This perhaps the imprisonment lead to promote health difficulty; for instance the drug abuser who live in fear of violence outside prison, however feel a big relieved as living in the prison may provide security with a locked cell door. Moreover, the inmates benefitted for having the shelter, regular meals and reduction in drug consumption. To have an improved access to health services may be another reason for the change; inmates may be able to overcome the addiction and promote the mental health of which they are unable to do so in the community.

Two prime factors are strictly provide impact on the index and provide information to the prison authority that could develop specific prevention, care strategies and appropriate policies to enhance drug-abuse inmates' health. For example, healthy lifestyle can be improved through carrying out sports activities in a sustainable manner aids to enhance physical health during the period of imprisonment.

\section{CONCLUSION}

Since there are no reliable, response measures of health and many other possible indicators, factor analysis is most reliable technique for determining the drug abuse health status index. Two factors were determined after analyzing the data ten indicators. These two factors identified as mental and physical health.

The high factor loadings as the indication of good health while low factor loadings considered as bad health. The first factor (mental health) are extracted based on the strong factor loading $(>0.70)$ and associated with the highest percentage of variance. The percentage of variance reveals that $25.38 \%$ and $29.17 \%$ for physical and mental health respectively. Individual score for drug abuse inmates determined for the measurement of health index. In summarization, the five health groups are ranked with poor (3\%), bad (19\%), moderate (41\%), good (29\%) and excellent (8\%) respectively.

These random samplings does not imply the specific group of prison inmates' located in Malaysia prison. However, with this set of data, the prison authority could enable to rank the health status. The same procedure can be applied in further study to calculate the index 
number for comparisons across population, state or nation.

\section{ACKNOWLEDGEMENTS}

The study is funded by the Niche Research Grant Scheme (NRGS-KPT), UniSZA/NRGS/2013/RR057 Universiti Sultan Zainal Abidin (UniSZA).

\section{REFERENCES}

[1] World Health Organization (WHO). Home. 2003, http://www.who.int/en/

[2] World Health Organization (WHO). Social determinants of health. 2006, http://www.who.int/social_determinants/en/

[3] Hightower W. Development of an index of health utilizing factor analysis. Medical Care, $1978,16(3): 245-255$

[4] Herbert K, Plugge E, Foster C, Doll H. Prevalence of risk factors for non-communicable diseases in prison populations worldwide: A systematic review. The Lancet, 2016, 379(9830):1975-1982

[5] Gemina D, Andari T T, Kusuma I C. Consumer behavior on the choice of typical regional food products based on external and internal factors, perception, attitude and consumer preference. International Journal on Advanced Science, Engineering and Information Technology, 2013, 3(2):138-141

[6] Ware J, Sherbourne C. The MOS 36-item short-form health survey (SF-36): I. Conceptual framework and item selection. Medical Care, 1992, 30(6):473-483

[7] Lioy P J, Zelenka M P, Cheng M D, Reiss N M, Wilson W E. The effect of sampling duration on the ability to resolve source types using factor analysis. Atmospheric Environment (1967), 1989, 23(1):239-254

[8] Soares P, Bruns R, Scarminio I. Statistical mixture design-Varimax factor optimization for selective compound extraction from plant material. Analytica Chimica Acta, 2008, 613(1): $48-55$

[9] Liu C W, Lin K H, Kuo Y M. Application of factor analysis in the assessment of groundwater quality in a Blackfoot disease area in Taiwan. Science of the Total Environment, 2003, 313(1-3): 77-89 
[10] Juahir H, Zain S M, Yusoff M K, Hanidza T T, Armi A M, Toriman M E, Mokhtar M. Spatial water quality assessment of Langat River Basin (Malaysia) using environmetric techniques. Environmental Monitoring and Assessment, 2011, 173(1-4):625-641

[11] Leung J, Pachana N, McLaughlin D. Social support and health-related quality of life in women with breast cancer: A longitudinal study. Psycho-Oncology, 2014, 23(9):1014-1020

[12] Antony G M, Rao V K. A composite index to explain variations in poverty, health, nutritional status and standard of living: Use of multivariate statistical methods. Public Health, 2007, 121(8):578-587

[13] United Nations Asia and Far East Institute for the Prevention of Crime and the Treatment of Offenders (UNAFEI). Group 2: Administration of penal institutions. 2005, http://www.unafei.or.jp/english/pdf/RS_No67/No67_14RC_Group2.pdf

[14] Aritonang E, Siregar S, Inayah E, Nasution E. The relationship of food consumption and nutritional status on employee of Health Polytechnic Directorate Health Ministry Medan. International Journal on Advanced Science, Engineering and Information Technology, 2016, 6(1):104-106

\section{How to cite this article:}

Mohamad M, Juahir H, Ali NAM, Kamarudin MKA, Karim F, Badarilah N. Developing health status index using factor analysis. J. Fundam. Appl. Sci., 2017, 9(2S), 82-92. 